\title{
MAQUINACIÓN Y SISTEMA DE MANIPULABILIDAD. UN DIÁLOGO ENTRE MARTIN HEIDEGGER Y KAREL KOSÍK
}

\author{
MACHINATION AND MANIPULABILITY SYSTEM. A DIALO- \\ GUE BETWEEN MARTIN HEIDEGGER AND KAREL KOSÍK
}

Jordi Magnet Colomer ${ }^{1}$

Recibido: 10/12/2016

Aceptado: 11/02/2016

\begin{abstract}
Resumen: El concepto de "maquinación” (Machenschaft) ocupa un lugar central en la obra de Heidegger durante el período comprendido entre 1936 y 1940. En su análisis de la esencia de la época moderna, el filósofo checo de orientación marxista Karel Kosík se apropia de importantes elementos conceptuales procedentes de esta etapa del pensamiento de Heidegger. En concreto, emplea nociones análogas a la de "maquinación", como "sistema de manipulabilidad". Ponemos de relieve las semejanzas y puntos de fricción en la descripción de la esencia de la época moderna de ambos pensadores, así como sus respectivas propuestas para poner coto a la primacía técnica y al pensamiento calculador y las resonancias políticas derivadas de sus análisis.
\end{abstract}

Palabras-clave: Machenschaft; maquinación; sistema de manipulabilidad; Heidegger; Kosík.

Abstract: The concept of "Machination" (Machenschaft) occupies a central pla-

1. Licenciado en Sociología y doctor en Filosofía por la Universidad de Barcelona (UB). Miembro del comité editorial de Oxímora. Revista Internacional de Ética y Política y de la Sociedad de Estudios de Teoría Crítica (SETC). Ha sido profesor visitante en la Universidad de El Salvador (UES). Últimas publicaciones: "Ontología de la sociedad unidimensional y crítica de la racionalidad tecnológica. El influjo de M. Heidegger en la obra tardía de H. Marcuse”, Devenires. Revista de Filosofía y filosofía de la cultura, $\mathrm{n}^{\circ}$ 35, 2017, pp. 41-72; "Entre la ontología heideggeriana y la marxiana. H. Marcuse y su interpretación de la manuscritos parisinos de Marx", Revista de Humanidades y Ciencias Sociales, no 8, julio-diciembre 2016, pp. 123-144; "Karel Kosík, marxismo y heideggerianismo en los albores de la Primavera de Praga", Laguna: Revista de Filosofía, n 35 , 2014, pp. 111-130. 
ce in Heidegger's work during the period between 1936 and 1940. In his analysis of the essence of the Modern Age, the Marxist-oriented czech philosopher Karel Kosík appropriates important conceptual elements from this stage of Heidegger's thought. In particular, he employs analogous notions to "Machination", as "Manipulability System". We highlight the similarities and points of friction in the description of the essence of the Modern Age in both thinkers, as well as their respective proposals to limit technical primacy and calculative thinking and political resonances derived from their analysis.

Key-words: Machenschaft; Machination; Manipulability System; Heidegger; Kosík.

\section{La esencia de la época moderna}

El repertorio conceptual manejado por el filósofo checo Karel Kosík (1926-2003) para revelar y poner en tela de juicio la esencia de la época moderna está en deuda con las nociones heideggerianas de "maquinación" (Machenschaft) ${ }^{2}$ y das Gestell, si bien aparecen expresadas en otros términos homologables, que no desvirtúan en nada su sentido primigenio en Heidegger, como "sistema de manipulabilidad". Estrechamente emparejado con el concepto de "maquinación", el fenómeno de lo "gigantesco" (das Riesige), objeto de escrutinio por parte de Heidegger en Meditación (1938-39) y en "La época de la imagen del mundo" (1938), es empleado también, aunque en una orientación algo distinta y actualizada, por el último Kosík. El diagnóstico epocal del filósofo checo converge en sus lineamientos generales con el de Heidegger, y así lo atestigua no sólo la similitud en el argot empleado, sino además la pasmosa coincidencia a la hora de precisar los orígenes y las secuelas -funestas a juicio de ambos- del sometimiento exacerbado del ente al cálculo y a la planificación en la época moderna. Ahora bien, las analogías cesan cuando reparamos en las disímiles propuestas a las que apelan ambos autores para paliar

2. El concepto de "maquinación" asume una creciente preponderancia en los Beiträge zur Philosophie (Vom Ereignis) (1936-38), en Besinnung (1938-39) y en Die Geschichte des Seyns (1938-40), que corresponden, en este mismo orden, a los tomos 65, 66 y 69 de la Gesamtausgabe. Las tres obras han sido vertidas al castellano por Dina V. Picotti: Aportes a la filosofía. Acerca del evento. Buenos Aires: Biblos, 2003; Meditación. Buenos Aires: Biblos, 2005 y La historia del ser. Buenos Aires: El Hilo de Ariadna, 2011.

Thémata. Revista de Filosofía N56 (2017) pp.: 235-254. 
o revertir el contexto de crisis civilizatoria, esto es, para contrarrestar la situación de riesgo y vulnerabilidad a la que se hallan abocados una humanidad y un planeta cada vez más supeditados a los designios de la maquinación o la manipulación. Además, la apropiación por parte de Kosík de elementos de examen conceptuales procedentes del aparato analítico heideggeriano también viene asociada a una crítica de tonalidades políticas dirigida al pensador alemán.

El tránsito de la ontología fundamental a la historia del ser, del decisionismo a la Gelassenheit, «del pathos de la autoafirmación al pathos del dejar-ser y de la obediencia $»^{3}$, no asume en Heidegger la forma de una completa ruptura, en el sentido de un total abandono de determinadas preocupaciones teóricas iniciales. Surgen ciertamente otras nuevas, pero el interés que induce a preguntar por el ser y, en consecuencia, por su olvido en la tradición metafísica occidental y en las sociedades modernas, se mantiene intacto. Sin embargo, como consecuencia del desplazamiento del centro de gravedad filosófico, la dirección donde apuntan ahora los análisis experimenta un desvío respecto al eje previo en que venía sustentada la ontología fundamental. Lo que acontece en este giro (Kehre) es más bien una profunda reconsideración de problemáticas que en su etapa anterior Heidegger sólo había mentado y apuntado accesoriamente. En este sentido, cuando tratamos de establecer ciertas reminiscencias que apunten a una prematura gestación del concepto de "maquinación" debemos retroceder hasta la analítica existenciaria de Ser y tiempo, en cuyas páginas puede hallarse, de un modo todavía embrionario, el germen de dicha noción.

Cuando en Ser y tiempo Heidegger contrapone la interpretación existencial y vulgar de la conciencia argumenta que en la cotidianidad prevalece la tendencia a considerar al Dasein como «objeto de manejo y cálculo», como "una cuestión administrativa» ${ }^{4}$. En lugar de concebir su especificidad constitutiva como potencialidad o poder-ser, el existir del Dasein se entiende como un mero negocio, «dentro de la idea de un trámite regulable» ${ }^{5}$. Esta tendencia es puesta en relación con la interpretación vulgar de la conciencia y su corolario, la teoría de los valores. La voz de la conciencia, que es característica de esta interpretación vulgar, tiende a requerir al Dasein el «cumplimiento de normas» o la "realización de valores» y a indicarle, a su vez, «posibilidades de acción» «disponibles, calcu-

3. Habermas, J.: "Heidegger: socavación del racionalismo occidental en términos de una crítica a la metafísica", en El discurso filosófico de la modernidad. Madrid: Taurus, 1989, p. 195.

4. Heidegger, M.: Ser y tiempo. Madrid: Trotta, 2009, pp. 305 y 309.

5. Ibídem, p. 309.

Thémata. Revista de Filosofía N56 (2017) pp.: 235-254. 
lables y seguras» ${ }^{6}$. Por el contrario, la llamada de la conciencia, característica de la interpretación existencial, no ofrece al Dasein «instrucciones prácticas sino que lo intima "al poder-sí-mismo propio» ${ }^{7}$. Heidegger hace partícipe de la concepción vulgar de la conciencia, así como de su traducción en términos prácticos (calculabilidad), tanto a la idea del deber moral kantiano como a la "ética material de los valores" de Max Scheler. De un modo similar, en el segundo tomo de Nietzsche (1939-1946), Heidegger reemprende de nuevo la crítica a la "maquinación" vinculándola explícitamente a la remisión a "valores". La carencia de sentido, propia de la época de las cosmovisiones en que impera la "maquinación", es suplida mediante el siguiente procedimiento: la interrogación por la verdad del ser es reemplazada por «la proposición maquinante de 'fines' (valores)»8. Es decir, en la época del acabamiento y la culminación de la metafísica, cuando la vida en su totalidad es sometida a un proceso de "movilización total" (Ernst Jünger) en términos puramente maquinadores, se torna preciso el establecimiento de nuevos valores. La pregunta por la esencia de la verdad cae entonces en el olvido y "todo pasa a referirse a un 'arreglárselas' y a algunos 'valores'»?.

Siendo la calculabilidad maquinadora un rasgo atribuible a la comprensión vulgar de la conciencia en Ser y tiempo, el concepto de "maquinación" como tal no aparece propiamente en el léxico de Heidegger hasta la Introducción a la metafísica (1935), y desde entonces adquiere un protagonismo difícilmente subestimable en su descripción de la esencia de la época moderna. Sin embargo, con posterioridad al estudio sobre Nietzsche, esto es, a partir de mediados de la década de los cuarenta, el término "maquinación" se substituye gradualmente por la noción de Gestell (traducida a menudo como "estructura de emplazamiento").

La historia occidental aparece caracterizada en la Introducción a la metafísica como intrínsecamente ligada a una caída fuera del ámbito del ser. A juicio de Heidegger, tal caída "conduce a la decadencia» ${ }^{10}$. La manifestación visible y superficial de esta decadencia discurre generalmente bajo la forma de "quehaceres y maquinaciones del hombre dentro de lo materialmente existente y disponible» ${ }^{11}$. La "violencia" (Gewalt) se nos presenta, además, como un elemento indisociable de esta "maquina-

6. Ídem.

7. Ibídem, p. 310.

8. Heidegger, M.: Nietzsche. Barcelona: Ariel, 2013, p. 538.

9. Ibídem, p. 540.

10. Heidegger, M.: Introducción a la metafísica. Barcelona: Gedisa, 2001, p. 42.

11. Ibídem, p. 64.

Thémata. Revista de Filosofía №56 (2017) pp.: 235-254. 
ción"12. Pero Heidegger no ofrece todavía al lector una definición precisa de lo que hay que entender específicamente por "maquinación”. Sí lo hace años más tarde, concretamente en la obra Meditación:

Maquinación significa aquí todo lo hacible del ente que se hace y constituye, de modo que tan sólo en ella se determina la entidad del ente abandonado por el ser (Seyn) (y la fundación de su verdad). (Hacible está pensado aquí como 'despertable' = alerta y por ello lo hacible en el sentido de lo hacedero). La maquinación es el prepararse para lo hacedero de todo, de modo que está dispuesto a lo irresistible del incondicional poner en cuenta de cada $\operatorname{cosa}^{13}$.

A través de la "maquinación", lo real se interpreta metafísicamente como voluntad de poder y la esencia del ser es concebida como presenciarse (Anwesen) y estabilidad (Beständigkeit) ${ }^{14}$. El ser es abandonado al ente y la esencia de la verdad es pensada erróneamente como certeza. Los análisis de Heidegger y Kosík concuerdan a la hora de responsabilizar al subjetivismo moderno cartesiano como el detonante filosófico de esta aprehensión calculadora de lo real como disponibilidad. Baste recordar al respecto la crítica de Heidegger a la metafísica de Descartes en "La época de la imagen del mundo" (1938). Continuadora de legado cartesiano es incluso la obra de Nietzsche, pues en ella la interpretación de lo ente y de la verdad se mantiene dentro de los límites inaugurados y fijados por Descartes ${ }^{15}$. Todavía más, la "voluntad de poder" nietzscheana culmina y consuma la metafísica occidental como máxima expresión de la misma. Por su parte, Kosík también concibe «la técnica y la ciencia modernas, con todas sus conquistas y descubrimientos, como un resultado de la filosofía de Descartes» ${ }^{16}$. Así, la disponibilidad total de lo existente, supeditada a una razón centrada enteramente en el sujeto, convierte a la naturaleza en "un número infinito de figuras combinales»"17. Cuando el mundo es transformado por el sujeto -cuyo correlato filosófico es el sujeto cartesiano- en objeto de control y dominio, el pensamiento calculador propio

12. Ibídem, p. 147.

13. Heidegger, M.: Meditación cit., p. 30.

14. Ibídem, p. 38.

15. Heidegger, M.: "La época de la imagen del mundo", en Caminos del bosque. Madrid: Alianza, 2012, pp. 72, 80 y 81.

16. Kosík, K.: Reflexiones antediluvianas. México: Itaca, 2012, p. 192.

17. Ibídem, p. 193.

Thémata. Revista de Filosofía №56 (2017) pp.: 235-254. 
de la ciencia moderna puede desplegarse triunfalmente sin hallar apenas oposición alguna en su camino.

La idea cartesiana de la verdad como certeza, donde la certeza es descifrada según los parámetros de la factibilidad (Machbarkeit) y la factualidad (Machsamkeit) ${ }^{18}$, contribuye, según Heidegger, al "origen de la devastación terráquea» ${ }^{19}$. En la época del acabamiento de la modernidad se impone por doquier el poder de la técnica sobre el ente, de tal suerte que la relación que el ser humano constituye con el mundo y con la naturaleza aparece mediada y determinada en su totalidad por la perspectiva técnica. Es sabido que en Heidegger la técnica no es nunca abordada desde un punto de vista antropológico ni instrumental; dicho en otros términos, la técnica no es para él una actividad humana (definición antropológica) ni un medio para un fin (definición instrumental) sino un peculiar modo de develamiento (Entbergen) del ser que atañe al ámbito de la verdad, a la aletheia. Sin embargo, la técnica moderna es un desocultar provocante del ser que "pone ante la Naturaleza la exigencia de suministrar energía que como tal pueda ser extraída y almacenada ${ }^{20}$. La naturaleza deviene un almacén de existencias (Bestand), «una única gigantesca estación de gasolina» ${ }^{21}$ cuyo único fin es abastecer al sujeto moderno, satisfaciendo así su creciente -e insostenible- sistema de necesidades.

Los rasgos típicos de la esencia de la técnica moderna son, pues, la calculabilidad y la acumulación. Por el contrario, en la poiesis griega la técnica no era un provocar sino un producir. La techné era para los pensadores griegos fuerza creativa vinculada a la fysis y a la aletheia. No era, en ningún caso, un provocar o un acumular. Tanto es así que, en opinión de Kosík, la injusticia en la era moderna «no radica (exclusivamente) en la distribución sino (ante todo) en el modo como esa riqueza se obtiene: la abundancia y el crecimiento van de la mano con la devastación del paisaje (la naturaleza) y del alma, de todo aquello que los griegos denominaban con una sola palabra, fysis» ${ }^{22}$. Si el origen filosófico de esta situación planetaria encuentra un punto de partida necesario en la obra de Descartes, en el plano político-social el análisis debe remontarse a la transición de la sociedad feudal al capitalismo. Según Kosík, el paradigma de la época moderna se asienta en una asociación fatal entre libertad

18. Cf. Heidegger, M.: La historia del ser cit., p. 24 y Nietzsche cit., p. 538.

19. Heidegger, M.: "Superación de la metafísica", en Conferencias y artículos. Barcelona: Ediciones del Serbal, 1994, p. 89.

20. Heidegger, M.: "La pregunta por la técnica", en Conferencias y artículos cit., p. 17.

21. Heidegger, M.: Serenidad. Barcelona: Ediciones del Serbal, 2002, p. 23.

22. Kosík, K.: Reflexiones antediluvianas cit., p. 227.

Thémata. Revista de Filosofía N56 (2017) pp.: 235-254. 
y dominio. Por una parte, el sujeto moderno, ayudándose de una razón recién emancipada, logra liberarse de las ataduras religiosas, sociales y políticas de la Edad Media. Por otra parte, esa libertad corre paralela a un dominio creciente sobre el medio natural ${ }^{23}$. El hombre pasa a convertirse en "dueño y señor" de la naturaleza ${ }^{24}$. El dominio instituido sobre la realidad, al que contribuye notablemente el sistema de ciencia, técnica y economía, convierte a ésta "en algo calculable y disponible que está al servicio del hombre ${ }^{25}$. De ahí que Kosík pueda caracterizar la metafísica de la época moderna como una conversión de "todo" en objeto de manipulación ${ }^{26}$.

\section{Abandono de la primacía técnica y del pensamiento calculador}

La salida de emergencia a este contexto de manipulación, devastación y decadencia, donde las cosas, el ser humano y la naturaleza son sometidos sin reparo alguno al cálculo maquinante, debe pasar necesariamente por una mayor acotación, dentro de los límites que le son propios, de la perspectiva técnica de la realidad ${ }^{27}$. Ahora bien, el cambio de paradigma requerido no sobrevendrá recurriendo a dudosos antídotos de tipo místico, cualquiera que sea el misticismo al que uno decida adscribirse. Para Heidegger, la huida hacia la mística no es más que «la mera

23. Sobre la dualidad libertad-dominio cfr. Kosík, K.: Reflexiones antediluvianas cit., p. 108 y Kosík, K.: "Praga y el fin de la historia. Entrevista con Alain Finkielkraut", Vuelta, 1994, p. 10. Cabría considerar aquí en qué medida la interpretación de Kosík acusa también una recepción de las tesis de Adorno y Horkheimer en Dialéctica de la Ilustración (1944), donde la crítica al proceso de dominio de la naturaleza como legado antagónico (libertad-dominio) recibido de la tradición ilustrada ocupa un lugar muy destacado en el corpus de la obra.

24. Repárese en la afinidad que este dictamen de Kosík guarda con algunas afirmaciones de Heidegger en "La época de la imagen del mundo" o en la Carta sobre el humanismo: «El hombre, entendido en la Ilustración como ser con razón, no es menos sujeto que el hombre que se comprende como nación, que se quiere como pueblo, se cría como raza y finalmente se otorga a sí mismo poderes para convertirse en dueño y señor del planeta». (Heidegger, M.: "La época de la imagen del mundo", en Caminos del bosque cit., p. 89); y: «El hombre no es el señor de lo ente. El hombre es el pastor del ser». (Heidegger, M.: Carta sobre el humanismo. Madrid: Alianza, 2010, p. 57).

25. Kosík, K.: Reflexiones antediluvianas cit., p. 108.

26. Ibídem, p. 44.

27. En Nuestra crisis actual (1968), Kosík contrapone de este modo el intelecto técnico a la razón dialéctica: «la razón dialéctica, como contraria al intelecto técnico, no significa contestación de la técnica y destrucción del intelecto técnico, sino simplemente afirmación de los límites dentro de los cuales la técnica y el intelecto técnico son válidos». Cf. Kosík, K.: La nostra crisi actual. Barcelona: Edicions 62, 1971, p. 61.

Thémata. Revista de Filosofía N56 (2017) pp.: 235-254. 
imagen contraria de la metafísica ${ }^{28}$. Por su parte, en Dialéctica de lo concreto, Kosík arguye que la esencia de la realidad no se manifiesta de forma directa e inmediata y, por consiguiente, la humanidad debe dar un rodeo si desea acceder a ella. Sin embargo, el misticismo pretende ahorrarse el esfuerzo que ello supone "y quiere captar directamente la esencia de las cosas», siendo así «una expresión de la impaciencia humana por conocer la verdad» ${ }^{29}$.

Pero si la crítica heideggeriana de la modernidad no recurre al misticismo tampoco se respalda en cuestiones de naturaleza normativa. Como hemos podido ver, la apelación a "valores" es rechazada tajantemente por Heidegger. "Los 'valores' son los ideales definitivamente flexionados hacia lo calculable, los únicos que resultan utilizables para la maquinación» ${ }^{30}$. No ocurre así, sin embargo, para el filósofo checo. Según Kosík, cuando el ser humano se convierte en una simple pieza del funcionamiento del sistema técnico-industrial, el sentido de la moral y de la cultura sufre una profunda alteración. El intelecto técnico, como pensar predominante en el seno del paradigma moderno, no tiene por objeto el desarrollo de una vida buena o ética sino de una "vida fácil y entretenida". La moral es juzgada como improductiva, y lo que viene a imponerse en su lugar es "una serie acordada de reglas de comportamiento y actuación» ${ }^{31}$, es decir, la ética se sustituye por códigos de conducta consuetudinarios. En tales circunstancias, Kosík considera que la praxis degenera en practicismo y manipulación, y la relación que se establece con la naturaleza está orientada en un sentido meramente técnico ${ }^{32}$.

La convergencia de pareceres entre ambos autores vuelve a ser ostensible cuando procuran elucidar las derivaciones lógicas de la vorágine desenfrenada de la técnica moderna y de la manipulación. En este punto, la coincidencia estriba en otorgar un papel relevante al nihilismo. Como es sabido, la relación de la técnica con el nihilismo es largamente atendida en la obra de Heidegger, sobre todo en los dos volúmenes sobre Nietzsche. Para el pensador alemán, Nietzsche es el filósofo arquetípico de la época de la consumación de la metafísica. Una época donde el dominio de la técnica va de la mano del poder del nihilismo. Inmerso en un pensar esencial del ser, Heidegger escribe que «la esencia del nihilismo es el estado de abandono del ser, en tanto que en él se produce el hecho

28. Heidegger, M.: Nietzsche cit., p. 544.

29. Kosík, K.: Dialéctica de lo concreto. México: Grijalbo, 1967, p. 39.

30. Heidegger, M.: Nietzsche cit., p. 544.

31. Kosík, K.: Reflexiones antediluvianas cit., pp. 110, 137 у 239.

32. Kosík, K.: "Dialéctica de la moral y moral de la dialéctica", en El hombre nuevo. Barcelona: Martínez Roca, 1969, pp. 95 y 102.

Thémata. Revista de Filosofía N56 (2017) pp.: 235-254. 
de que el ser se deja ir a las maquinaciones. Este dejarse ir sojuzga al hombre en una servidumbre incondicionada $»^{33}$. Igualmente, el siglo XX es descrito por Kosík como la época del «fin de la historia» y del «nihilismo desatado ${ }^{34}$. El nihilismo aparece, pues, como el producto esperado del sistema de manipulabidad general, en el que todo deviene intercambiable y equivalente -incluidos los valores, la idea del bien y del mal, lo verdadero y lo falso-, en el que los hombres se reifican y las cosas se desreifican ${ }^{35}$.

Conviene señalar aquí, empero, que Kosík no haría del todo suyo el análisis del nihilismo occidental, al menos en la forma como ha sido desarrollado ulteriormente por el llamado "pensamiento débil" (Vattimo). Según Heidegger, lo que arrastra a nuestra época al nihilismo no es tanto la "maquinación", que sería más bien una secuela o un acontecimiento acaecido paralelamente al nihilismo, sino la omisión de la pregunta por la esencia de la nada (y la omisión de la pregunta por el ser). La teología negativa que emana de este interrogarse por la esencia de la nada ${ }^{36}$, donde la nada es pensada como aquello que resta a resguardo de la "maquinación" en la era de la "movilización total" (E. Jünger), es apropiada y reinterpretada por la "izquierda heideggeriana" de nuestros días. Llevando hasta un punto de no retorno los preceptos de Heidegger, el "pensamiento débil", totalmente distanciado del pensar metafísico de la tradición occidental, decide no recurrir a fundamentaciones de ningún tipo. Le basta con enarbolar la dimensión de la nada o de la ausencia (Abwesen) frente a la dimensión de la presencia (Anwesen) ${ }^{37}$. Si a diferencia de Vattimo y sus condiscípulos, Kosík no rompe abrupta y definitivamente con la tradición metafísica, abrazando sin reservas este nihilismo renovado inspirado en el Heidegger posterior a la Kehre, ello se debe a las fuertes resonancias marxistas detectables en el conjunto de su obra. Un marxismo ciertamente heterodoxo que, pese a no ser dogmático, esto es, a pesar de no emplearse vulgarmente como metafísica especulativa de las leyes de la naturaleza y de la historia, continúa bebiendo de las fuentes

33. Heidegger, M.: "Superación de la metafísica”, en Conferencias y artículos cit., pp. 81-82.

34. Kosík, K.: Reflexiones antediluvianas cit., p. 110.

35. Kosík, K.: La nostra crisi actual cit., p. 60.

36. Como es sabido, Heidegger se ocupó extensamente de la elaboración -y la respuesta- de la pregunta por la nada en ¿Qué es metafísica? (1929). Por esta razón, es preciso afrontar su estudio sobre Nietzsche tomando en consideración los argumentos ahí desarrollados, donde la nada aparece como el fundamento del carácter ontológico y teológico de la metafísica.

37. Véase, por ejemplo, Vattimo, G.: Más allá del sujeto. Nietzsche, Heidegger y la hermenéutica. Barcelona: Paidós, 1992, p. 73 y Las aventuras de la diferencia. Pensar después de Nietzsche y Heidegger. Barcelona: Península, 1988, p. 114.

Thémata. Revista de Filosofía N56 (2017) pp.: 235-254. 
del idealismo alemán y, por este motivo, a ojos del "pensamiento débil" permanecería todavía arraigado en la metafísica occidental.

Al preguntar por la esencia de la técnica, Heidegger pretende poner fin a la primacía del pensamiento calculador. Las fórmulas anteriores a las que había recurrido con el propósito de liberarse de la hegemonía de la "maquinación" concedían esa función al ámbito del Ereignis (evento apropiador) y del pensar meditativo. Así, en Meditación, el Ereignis aparece como el acontecimiento encargado de devolver el ente a su pertenencia al ser ${ }^{38}$. En cercana conexión con él, el pensamiento meditativo no prolonga en absoluto el pensar según los cánones de la metafísica tradicional. Contrariamente a esta última, la meditación está enraizada en la esencia del ser y tiene por objeto interrogarse acerca de su verdad. Representa, pues, un pensar «más originario», un "salto» al pensar según la «historia del ser» ${ }^{39}$. Ereignis y pensar meditativo suponen una vía de escape al despotismo de la calculabilidad maquinante como paradigma dominante de la modernidad. Para Kosík, tampoco se trata de proponer un mero cambio dentro del paradigma moderno contemporáneo, sino de transformar y renunciar de manera integral a este paradigma. En la actual coyuntura, dice Kosík, ya no podemos limitarnos a «defender el entorno» (Umwelt), permaneciendo así enteramente en las entrañas del paradigma moderno; de lo que se trata es de "salvar el mundo» (Welt), reemplazando por completo este paradigma mediante una transformación radical «de la relación fundamental y fundadora que las personas tienen con lo que es, incluido su propio yo» ${ }^{40}$. El ser humano está determinado por su relación con la verdad (aletheia), pero el sistema moderno entorpece enormemente la correspondencia del ser del hombre con la verdad ${ }^{41}$.

Nos interesa resaltar ahora aquellos puntos donde el análisis de Kosík parece mostrar ciertas fricciones respecto al planteado por Heidegger. Como observa con razón Habermas, la crítica a la modernidad de Heidegger no tiene en cuenta la diferencia entre razón y entendimiento. La razón es reducida a entendimiento. Todo ello culmina en un proceso de destrucción de la razón moderna al precio de una nivelación inaceptable de sus distintas acepciones, donde "ya no distingue entre los contenidos universalistas del humanismo, de la Ilustración e incluso del positivismo, de un lado, y las ideas de autoafirmación particularista anejas al racismo y al nacionalismo o a tipologías regresivas al estilo de Spengler

38. Heidegger, M.: Meditación cit., p. 29.

39. Ibídem, p. 35.

40. Kosík, K.: "Praga y el fin de la historia. Entrevista con Alain Finkielkraut" cit., p.11.

41. Kosík, K.: Reflexiones antediluvianas cit., p. 110.

Thémata. Revista de Filosofía №56 (2017) pp.: 235-254. 
y de Jünger, de otro» ${ }^{42}$. Paradójicamente, Heidegger valida así la reducción de la razón en general a razón instrumental. De este modo, al corroborarlo implícitamente, la filosofía sucumbe irremediablemente al espíritu de un tiempo que juzga controvertido, en lugar de distanciarse de él. Kosík, en cambio, se opone con firmeza al proceso de "transformación de la imaginación creativa en inventiva técnica» ${ }^{43}$. Para él, la confusión moderna entre razón y racionalización, o entre razón y entendimiento, no conlleva, como en Heidegger, el abandono de una crítica racionalmente sustentada.

A pesar de tener en alto grado de consideración la descripción heideggeriana de la esencia de la técnica como das Gestell ${ }^{44}$, las credenciales marxistas de Kosík impiden que el filósofo checo pueda adherirse sin fisuras a los análisis de Heidegger sobre la técnica moderna. El punto más problemático a este respecto radica en la consideración del Gestell como destino. En ocasiones Heidegger da a entender que la esencia de la técnica moderna constituye un destino o una fatalidad de la que no es posible eludirse. El decisionismo de Ser y tiempo concebía todavía la oportunidad de acceder a un ámbito de autenticidad a través del acto resolutorio del Dasein. Por el contrario, la esencia de la técnica moderna, ¿es forzosamente un destino inevitable? Herbert Marcuse advirtió que en Heidegger la técnica y la tecnología se presentan como potencias en sí mismas, independientemente de la función y el uso que imprimen en ellas las relaciones de poder realmente existentes en la sociedad ${ }^{45}$.Y, en verdad, esto es lo que puede deducirse al leer determinadas aserciones de Heidegger en La pregunta por la técnica. La esencia de la técnica sitúa al ser humano en la senda del develamiento, esto es, en un camino destinal que no depende de su voluntad. Una concepción tal es difícilmente insertable en el marco de una teoría marxista heterodoxa como la de Kosík. Encajaría sin demasiados problemas en las corrientes vulgares y cientificistas del marxismo (II Internacional, marxismo soviético, etc.), donde la praxis desaparece o trueca en espejismo, cediendo todo el protagonismo del devenir societario a unas leyes objetivas de la historia que discurren completamente al margen de la decisión humana. No obstante, plantear semejante cuestión basándola en los argumentos precedentes implicaría no atenderla desde todos sus ángulos, pues la problemática abordada en-

42. Habermas, J.: El discurso filosófico de la modernidad cit., p. 166.

43. Kosík, K.: Reflexiones antediluvianas cit., p. 110.

44. Sobre esto véase la extensa entrevista de Fornet-Betancourt, R. y Traine, M.: "Interview mit Karel Kosík", Concordia, n 24, 1993, pp. 13-23.

45. Olafson, F.: "Heidegger's politics: an interview with Herbert Marcuse", Graduate Faculty Philosophy Journal, no 1/vol.6, 1977, pp. 31-32.

Thémata. Revista de Filosofía N56 (2017) pp.: 235-254. 
cierra una complejidad mayor de la que parece aparentar a simple vista. Por un lado, Heidegger concibe el Gestell como un destino que amenaza seriamente a la humanidad, pero, por otro lado, también señala que alberga en sí "el crecimiento de lo que salva»" ${ }^{46}$. Por lo demás, como ya hemos señalado, con la apelación al Ereignis, que es simultáneamente un acto de trascendencia y de autoencuentro, Heidegger proyecta revertir la primacía del mundo técnico. Con el recurso al ámbito del Ereignis, la actual correlación de fuerzas, en la que el ser humano y el ente son siervos de una técnica que los domina, puede invertirse. El ser humano cesaría entonces de actuar como ejecutor de un "poder aniquilador» para erigir en su lugar un "señorío dignificante» ${ }^{47}$. Así, gracias al doble carácter amenazante y salvador del Gestell y al ámbito de trascendencia abierto a través del Ereignis, la presunta inevitabilidad del destino de la esencia de la técnica moderna -ya se designe esta esencia como Machenschaft o Gestell-, que pareciera escabullirse de cualquier tipo de control humano, es en cierto modo subsanada impidiendo que pueda atribuírsele erróneamente el carácter de una fatalidad ${ }^{48}$.

\section{Algunas consideraciones políticas}

Las resonancias políticas del diálogo entre ambos pensadores pueden ayudar a alumbrar la comprensión de ciertas dinámicas del capitalismo contemporáneo. Teniendo en mente tal propósito, la diatriba de Heidegger contra las distintas cosmovisiones totalitarias, que son juzgadas desde una misma óptica según los imperativos de la Machenschaft, no debería encuadrarse, como sucede con cierta frecuencia, a un período histórico ya dejado atrás (guerras mundiales, nazismo, stalinismo, guerra fría, etc.); antes bien, resulta del todo pertinente recurrir a ella -con

46. Heidegger, M.: "La pregunta por la técnica", en Conferencias y artículos cit., p. 30.

47. Heidegger, M.: Meditación cit., p. 30.

48. En este sentido, en la entrevista concedida en 1966 al diario Spiegel, Heidegger afirma: "Yo veo la situación del hombre en el mundo de la técnica planetaria no como un destino inextricable e inevitable, sino que, precisamente, veo la tarea del pensar en cooperar, dentro de sus límites, a que el hombre logre una relación satisfactoria con la esencia de la técnica». Cf. Heidegger, M.: La autoafirmación de la Universidad alemana. El Rectorado 1933-1934. Entrevista a Spiegel. Madrid: Tecnos, 1996, p. 77. 
cierta cautela- para poder dotar de renovadas herramientas conceptuales al pensamiento emancipador del tiempo presente.

Los fundamentos para el desarrollo de una filosofía política a partir de la obra de Heidegger se han buscado en la analítica existenciaria del Dasein (Hermann Mörchen) o en la crítica de la técnica moderna (Otto Pöggeler). Aunque en Dialéctica de lo concreto Kosík haga un uso crítico de la hermenéutica del Dasein, no sin distanciarse de ella en algunos aspectos decisivos, y en una etapa subsiguiente decida acudir a otros trabajos primordiales de Heidegger, como es el caso de La pregunta por la técnica, hemos comprobado cómo sus reflexiones de madurez muestran relevantes correspondencias con la etapa intermedia de la obra de Heidegger, ubicada entre la analítica existenciaria de Ser y tiempo y La pregunta por la técnica, es decir, la fase que abarca la década de los años treinta e inicios de los cuarenta -principalmente los Aportes, Meditación y La historia del ser.

Durante ese período, el comunismo, el americanismo y el fascismo son interpretados indistintamente por Heidegger como expresiones de la dominación metafísica ejercida por la técnica moderna ${ }^{49}$. Dejando a un lado el riesgo que supone equiparar estos tres sistemas de dominio tan disímiles entre sí, lo cierto es que Heidegger tampoco establece diferenciación alguna en el interior de esos mismos regímenes, concibiendo, por ejemplo, al comunismo, exclusivamente según su forma degenerada, ya se trate de bolchevismo o de stalinismo. Tanto es así que en La historia del ser, Heidegger llega a caracterizar a Rusia, y a todo el imaginario que lo envuelve, como "una ilimitada explotación empresarial de materias primas para las sutilezas de las 'máquinas' ${ }^{50}$. Por lo demás, al atribuir al fascismo solamente una lógica de racionalización tecnológica en la estela de la Machenschaft, el análisis pasa por alto los elementos irracionalistas que en el nacionalsocialismo coexisten con la razón instrumental así como la cuestión de la acrecentación de la dominación socio-política, por un lado, y de la represión y eliminación de la oposición y de determinadas minorías, por otro.

Procediendo de un modo muy distinto, Kosík distingue claramente el concepto de socialismo o comunismo originario de su versión soviética. Para el pensador checo, la esencia del socialismo no reside en la colectivización de los medios de producción ni en la organización científica de la sociedad -la denominada revolución técnico-científica- ${ }^{51}$ (en base a

49. Cf. J. Habermas, "Heidegger: socavación del racionalismo occidental en términos de una crítica a la metafísica”, en El discurso filosófico de la modernidad cit., p. 195.

50. Heidegger, M.: La historia del ser cit., p. 147.

51. Kosík, K.: La nostra crisi actual. cit., p. 46.

Thémata. Revista de Filosofía N56 (2017) pp.: 235-254. 
esta segunda acepción es como percibe globalmente Heidegger al comunismo), sino en la «liberación del sistema de manipulabilidad general $»^{52}$, esto es, en el intento de poner coto a la concepción de la realidad como algo calculable y disponible.

A finales de los años sesenta, recién iniciado el breve proceso de liberalización política en Checoslovaquia, todas las esperanzas de Kosík van a depositarse en el socialismo de rostro humano, en cuanto modelo contrapuesto no sólo al capitalismo democrático liberal (propiedad privada capitalista), a lo que Heidegger designa con el nombre de americanismo, sino también al stalinismo (propiedad estatal burocrática): «El stalinismo, sistema burocrático y policíaco de dominio absoluto, se basa en la idea de la manipulabilidad general de hombres y cosas, del hombre y la naturaleza, de las ideas y los sentimientos, de los vivos y los muertos ${ }^{53}$. En la aproximación a estos dos modelos estructurantes de la realidad, o cosmovisiones según el argot heideggeriano, Kosík muestra una amplitud de miras mayor que la de Heidegger, al reconocer, al menos, que el stalinismo burocrático y el capitalismo liberal son formaciones económicas distintas. Sin embargo, ambas comparten una concepción común del hombre y de la realidad marcada por la falsa conciencia y por la manipulación ${ }^{54}$. En uno y otro caso, el ser humano se ve reducido a material empírico, a un recurso disponible de antemano conocido. De modo que en la conciencia ordinaria cotidiana se forja «una determinada caracterización del carácter humano», un conjunto de creencias populares o sentido común, donde «el foco de atención no está en el carácter (la esencia) del hombre sino sólo en su funcionalidad». Esta sabiduría mundana encuentra una justificación de sus tesis dentro del sistema de manipulación general, pero «fuera de este sistema, las cualidades del hombre experimentan una transformación, y esta presunta sabiduría mundana -p.ej. el hombre es un lobo para el hombre, etc.- pierden su valor y significado» ${ }^{55}$. Probablemente sea en la doctrina política de Maquiavelo, así como en la concepción del "estado de naturaleza" de Hobbes, donde esta específica caracterización del ser humano recibe su máxima formulación y justificación en términos teóricos. En El Príncipe de Maquiavelo la política deviene una técnica manipulatoria, mientras que para Hobbes aquello

52. Ibídem, p. 56.

53. Ibídem, p. 55 .

54. Ibídem, p. 57.

55. Kosík, K.: "El hombre y la filosofía”, en E. Fromm (ed.), Humanismo socialista. Barcelona: Paidós, 1980, pp. 184-185.

Thémata. Revista de Filosofía №56 (2017) pp.: 235-254. 
que define el marco social es la lucha entablada entre todos los miembros de la sociedad por la autoconservación.

A ojos de Kosík, la crisis acaecida en Checoslovaquia durante la Primavera de Praga no fue en primer término una crisis de signo político o económico; fue más bien una «crisis de los fundamentos de la realidad como sistema de manipulabilidad general ${ }^{56}$. A lo largo de los escasos meses en que se prolongó la Primavera de Praga, tuvo lugar la gestación de una nueva configuración societaria consignada a trascender el sistema de manipulación en las dos vertientes mencionadas (stalinista y capitalista). Como es sabido, este nuevo paradigma, surgido en Checoslovaquia a principios del año 1968, fue aplastado militarmente al poco tiempo de iniciarse por las fuerzas del Pacto de Varsovia, y coaptado conveniente y tergiversadamente, con el fin de justificar intereses anticomunistas, por la mayoría de líderes políticos y medios de comunicación de los países occidentales. Puede decirse que la Primavera de Praga opera, pues, como un telos, es decir, como ejemplo de un posible horizonte de emancipación, en la obra del Kosík posterior a 1968. Incluso a inicios de la década de los noventa, todavía se esfuerza por extraer de ese relevante período histórico las lecciones necesarias que deberían conducir a la salvación de la humanidad por la vía de la imaginación creativa ${ }^{57}$. En su caso, no es, por tanto, el ámbito del Ereignis o del pensar meditativo lo que pondrá fin al dominio de la maquinación, sino el socialismo de rostro humano y la imaginación creativa.

Kosík no va a dar su brazo a torcer y mantendrá intacta la fidelidad al pensamiento de Marx durante toda su vida. Aun sirviéndose copiosamente de los análisis de Heidegger, a su juicio el sistema de manipulabilidad del siglo XX no es más que una variación del sistema mercantil del siglo XIX analizado por Marx. Se trata solamente de un desarrollo y de un perfeccionamiento que no ve alterados sus fundamentos ${ }^{58}$. Por esta razón, los esquemas interpretativos marxistas sustentados en la dicotomía valor de cambio-valor de uso, o bien en los conceptos de comercio, utilitarismo, alienación o fetichismo de la mercancía, conservan su validez para este nuevo escenario. Por lo demás, Kosík tampoco tiene ningún reparo en asemejar la misión histórica que Heidegger encomienda al

56. Kosík, K.: La nostra crisi actual cit., p. 55.

57. Kosík, K.: "Praga y el fin de la historia. Entrevista con Alain Finkielkraut" cit., p.11.

58. Kosík, K.: La nostra crisi actual cit., p. 56.

Thémata. Revista de Filosofía N56 (2017) pp.: 235-254. 
pueblo alemán, a saber, la salvación de Occidente de la doble amenaza representada por el americanismo y el sovietismo, con la teoría fascista:

en su diferenciación entre Europa, por una parte, y el bolchevismo antieuropeo (asiático) o el igualmente estéril 'americanismo', por la otra, Heidegger no expresa sus opiniones sino que rinde tributo al 'espíritu de la época', a la carencia de espiritualidad de la ideología de la época, que en versión propagandística vulgar comparten también durante la segunda guerra mundial los fascistas $\operatorname{checos}^{59}$.

En todo caso, la realidad predominante hoy en día, después de imponerse y consolidarse victoriosamente por encima de sus antagonistas a lo largo del convulso siglo XX, no es ni el fascismo ni el bolchevismo. Sin embargo, da la impresión de que la realidad actual tampoco encaja plenamente dentro de los ambiguos contornos del término "americanismo", entre otros motivos porque ya no tratamos aquí con un capitalismo al estilo tradicional. «El gobierno global del mundo no lo ejerce hoy el capitalismo tradicional, el sistema económico más productivo de la historia sino el Supercapital, que domina todos los aspectos de la vida humana, tiene su propia economía, su política, su moral, su cultura $»^{60}$. A diferencia del anterior modelo de reglamentación, las jerarquías se encuentran ahora más desdibujadas. El mundo es gobernado por un sistema funcional impersonal, administrado por los fenómenos de la cosificación, la anonimidad y la abstracción ${ }^{61}$. La condena con la que debe cargar el ser humano es la de desempeñarse como una pieza o «instrumento del funcionamiento técnico-industrial que dicta el tempo y el ritmo de vida, su modo de pensar y sentir» ${ }^{62}$. En la cúspide de esta particular ordenación societaria, Kosík ubica al «oculto dictador planetario»" ${ }^{63}$, es decir, al 'Supercapital'.

La relación del 'Supercapital' con la democracia es siempre tensa. Cuando la democracia supone un estorbo a su expansión, el 'Supercapital' no duda en utilizar los recursos de los que dispone para suspenderla temporalmente o, incluso, eliminarla. Poco después de la Revolución de Terciopelo de 1989, que supuso el fin del régimen comunista de Husák en Checoslovaquia, Kosík escribe, refiriéndose a su país natal, que la

59. Kosík, K.: Reflexiones antediluvianas cit., pp. 156-157. Concretamente, Kosík equipara las opiniones de Heidegger a la de fascistas checos como Emanuel Vajtauer y Karel Laznovsky.

60. Kosík, K.: Reflexiones antediluvianas cit., p. 241.

61. Ibídem, p. 223.

62. Ibídem, p. 137.

63. Ibídem, p. 223.

Thémata. Revista de Filosofía $\mathrm{N}^{\circ} 56$ (2017) pp.: 235-254. 
dictadura anónima de la policía y de la burocracia (stalinismo) ha sido reemplazada por la dictadura anónima del mercado y de su antiespíritu. No es la mano invisible de Adam Smith o el Espíritu absoluto de Hegel lo que regula el sistema social sino "un gigante oculto y anónimo», una auténtica tiranía del antiespíritu que emplea todo su poder para subordinar a los seres humanos, a la naturaleza y a la historia ${ }^{64}$. Esta dictadura es el basamento metafísico de nuestra época.

En el retrato que lleva a cabo Kosík del 'Supercapital' como un inmenso gigante planetario, encontramos claras reminiscencias a la descripción del fenómeno de lo "gigantesco" (das Riesige) en Heidegger:

Lo gigantesco es más bien aquello por medio de lo cual lo cuantitativo se convierte en una cualidad propia y, por lo tanto, en una manera especialmente señalada de lo grande. Cada época histórica no sólo es diferentemente grande respecto a las otras, sino que además tiene su propio concepto de grandeza. Pero en cuanto lo gigantesco de la planificación, el cálculo, la disposición y el aseguramiento, dan un salto desde lo cuantitativo a una cualidad propia, lo gigantesco y aquello que aparentemente siempre se puede calcular por completo, se convierten precisamente por eso en lo incalculable ${ }^{65}$.

La devastación, mezclada con el poder (Macht) y la prepotencia, como expresiones intrínsecas a la maquinación, es aquello que motiva el predominio de lo gigantesco. Con ello Heidegger mienta lo «sin-medida» ${ }^{66}$ de la época moderna, justamente en el punto donde lo calculable se transforma en incalculable («en la aniquilación de las grandes distancias gracias al avión, en la representación en toda su cotidianeidad, producida a placer y sin ningún esfuerzo, de mundos extraños y lejanos gracias a la radio» ${ }^{67}$, etc.). La desmesura, el rebasamiento de toda medida, junto a la inversión y la contraverdad, es también una de las características que Kosík atribuye al paradigma moderno ${ }^{68}$. El americanismo es considerado por Heidegger como un subgénero del gigantismo. Sin embargo, a juicio de Kosík, esta "tendencia de la época moderna» es un «fenómeno típicamente europeo» y, por tanto, supone un desacierto culpabilizar de esa específica tendencia al americanismo ${ }^{69}$. Ahora bien, aunque Kosík decida imputar a Heidegger esta discutible concepción, en "La época de

64. Ibídem, p. 235.

65. Heidegger, M.: "La época de la imagen del mundo", en Caminos del bosque cit., p. 78.

66. Heidegger, M.: La historia del ser cit., p. 70.

67. Heidegger, M.: "La época de la imagen del mundo", en Caminos del bosque cit., p. 77.

68. Kosík, K.: "Praga y el fin de la historia. Entrevista con Alain Finkielkraut" cit., p. 10.

69. Ibídem, p. 12.

Thémata. Revista de Filosofía N56 (2017) pp.: 235-254. 
la imagen del mundo" el pensador alemán también deja claro que el americanismo es "algo europeo»"

Quienes estimen que los análisis de Heidegger sobre el cálculo y la tecnificación han perdido toda vigencia, siendo solamente apropiados para dar cuenta de algunas dinámicas pretéritas, inherentes a los regímenes totalitarios de un pasado reciente, tienen aquí una batería de argumentos para reconsiderar sus planteamientos. El fenómeno de la globalización no deja de ser una lucha por el poder planetario animada por los imperativos de la Machenschaft. A fin de cuentas, el interés de la teoría marxista -al menos de aquella que, como la de Kosík, no está inserta en los engranajes del poder y la maquinación-, en aprehender el proceso mediante el cual en este contexto los seres y las cosas son uniformemente transformados en mercancías, donde las personas, prisioneras del sistema productivo, son rebajadas "al rango de productores y consumidores ${ }^{71}$, enlaza con la crítica al paradigma de la modernidad en las obras de Heidegger aquí consideradas.

\section{Referencias bibliográficas}

Fornet-Betancourt, R. y Traine, M.: "Interview mit Karel Kosík", Concordia, no 24, 1993, pp. 13-23.

Habermas, J.: El discurso filosófico de la modernidad. Madrid: Taurus, 1989.

Heidegger, M.: Conferencias y artículos. Barcelona: Ediciones del Serbal, 1994.

Heidegger, M.: La autoafirmación de la Universidad alemana. El Rectorado 1933-1934. Entrevista a Spiegel. Madrid: Tecnos, 1996.

Heidegger, M.: Introducción a la metafísica. Barcelona: Gedisa, 2001.

Heidegger, M.: Serenidad. Barcelona: Ediciones del Serbal, 2002.

Heidegger, M.: Aportes a la filosofía. Acerca del evento. Buenos Aires: Biblos, 2003.

Heidegger, M.: Meditación. Buenos Aires: Biblos, 2005.

Heidegger, M.: Ser y tiempo. Madrid: Trotta, 2009.

Heidegger, M.: Carta sobre el humanismo. Madrid: Alianza, 2010.

Heidegger, M.: La historia del ser. Buenos Aires: El Hilo de Ariadna, 2011.

Heidegger, M.: Nietzsche. Barcelona: Ariel, 2013.

70. Heidegger, M.: "La época de la imagen del mundo" cit., p. 90.

71. Kosík, K.: "Praga y el fin de la historia” cit., p. 10.

Thémata. Revista de Filosofía $\mathrm{N}^{\circ} 56$ (2017) pp.: 235-254. 
Heidegger, M.: Caminos del bosque. Madrid: Alianza, 2012.

Kosík, K.: Dialéctica de lo concreto. México: Grijalbo, 1967.

Kosík, K.: "Dialéctica de la moral y moral de la dialéctica", en Kosík, Leontiev, Luria et. altri.: El hombre nuevo. Barcelona, Martínez Roca, 1969, pp. 85-102.

Kosík, K.: La nostra crisi actual. Barcelona: Edicions 62, 1971.

Kosík, K.: "El hombre y la filosofía", en Fromm, E. (ed.): Humanismo socialista. Barcelona: Paidós, 1980, pp. 183-192.

Kosík, K.: "Praga y el fin de la historia. Entrevista con Alain Finkielkraut", Vuelta, 1994, pp. 9-13.

Kosík, K.: Reflexiones antediluvianas. México: Itaca, 2012.

Olafson, F.: "Heidegger's politics: an interview with Herbert Marcuse", Graduate Faculty Philosophy Journal, no 1/vol.6, 1977, pp. 28-40.

Vattimo, G.: Las aventuras de la diferencia. Pensar después de Nietzsche y Heidegger. Barcelona: Península, 1988.

Vattimo, G.: Más allá del sujeto. Nietzsche, Heidegger y la hermenéutica. Barcelona: Paidós, 1992. 
